\title{
Learning Performance Assessment using Mobile-Based Augmented Reality Application for Preschool Environment
}

\author{
Nur Iman Malini Muhamad Mahmud, Ismahafezi Ismail, Syadiah Nor Wan Shamsuddin, \\ Suhailan Safei, Mohd Azhar M. Arsad
}

\begin{abstract}
In the past ten years, technology and research in augmented reality (AR) have rapidly evolved in various fields, which led to a significant advancement in AR technology and application development. However, most of the recent development in AR are mainly focusing on how to overcome hardware and software issues. It is undeniable that overcoming technical problems are crucial in AR development and rapid development for technology advancement; however, it neglects the end user. This study presents learning performance assessment using mobile-based augmented reality application for Malaysian preschool in rural areas. This study used non probability sampling and a paired t-test to compare the data collected from the sample test. The students showed a significant interest in learning using augmented reality technology.
\end{abstract}

Index Terms - Augmented reality, learning performance assessment, mobile-based application, preschool environment.

\section{INTRODUCTION}

With the rapid advent of mobile augmented reality (AR) application on the market, exploring new advancement of this functionality of mobile application becomes a most exciting research study. Possible functionality that values the research in AR is a virtual button interaction on mobile AR applications. AR has many advantages that bring the unique possibility of merging the real world with a digital element, giving users the access to information in a practical yet intuitive way.

AR or known as a variation of the virtual environment is a technology that allows the computer to deploy virtual images over the real-world objects in real time by enhancing the real-life scenario with the artificial model. In [1] defined $\mathrm{AR}$ as a system that fulfils the following characteristics; a combination of a real world and virtual model, real-time interaction and registered in 3D of the virtual and tangible objects. As predefined, AR signifies a variation of virtual reality [2] and plays a substitute role rather than a replacement of reality.

Augmented reality cracks up a lot of possibilities for fun, immersing and a realistic game where users can actively interact with the game through AR mobile application. Physically, user interface interaction often becomes the

Revised Manuscript Received on July 10, 2019.

Nur Iman Malini Muhamad Mahmud, Universiti Sultan Zainal Abidin, Malaysia.

Ismahafezi Ismail, Universiti Sultan Zainal Abidin, Malaysia.

Syadiah Nor Wan Shamsuddin, Universiti Sultan Zainal Abidin, Malaysia.

Suhailan Safei, Universiti Sultan Zainal Abidin, Malaysia.

Mohd Azhar M. Arsad, V3X Malaysia Sdn. Bhd., Malaysia. main source for the application of usability principles design problem. Having a poor interaction design from a cognitive perspective always makes the user feel it is challenging to use the AR system [3], [4] as they are not familiar with the use of mechanical devices applying the AR system. Familiarity with the machine is essential though the physical difficulty of using AR is reduced as most people are familiar with mobile phone interaction design

Mobile phone is an ideal device to implement AR, but the properties of its physical button always have some critical issues. The physical button is pervasive [5]. The various properties of this button such as size, trigger, shape, travel distance, force and audible feedback contribute to the understanding that certain buttons operate in differently unique ways despite their diverse functionalities and properties. Besides, the lack of good Human factor design [6] for the passive interactive interface causes the users to view the scene merely augmented only with visual information, while augmented reality interface can be made interactive.

\section{MOBILE-BASED AUGMENTED REALITY APPLICATION}

Augmented reality has extensively grown as various AR related research topics have been developed and discussed. Researchers have mainly focused on these five cores of AR technology area that is; tracking technique, interaction technique and user interface, AR application, rendering and visualisation, evaluation and display technique [7]. Therefore, a variety of AR techniques have been proposed in the rising demand of the AR technology that can potentially imply to all senses including hearing, touch and smell [8]. For instance, the augmented mirror where a virtual character can interact with an audience in real time, which can mimic facial expression, lip movement and movement [9]. This application integrates video images, avatar and other virtual objects within the AR system implemented by a mixture of technology; two Kinect systems for motion capture, a depth map and real images, as well as control algorithm to manage avatar emotion.

Many factors influence the trends and accomplishment in AR research evolution for the past years. Interaction techniques and user interfaces focus on the techniques and

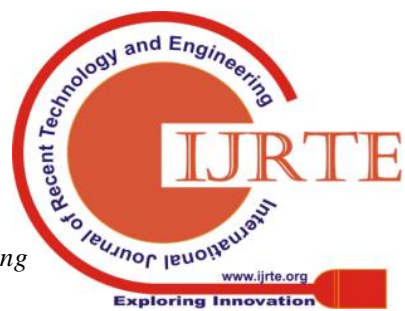




\section{LEARNING PERFORMANCE ASSESSMENT USING MOBILE-BASED AUGMENTED REALITY APPLICATION FOR PRESCHOOL ENVIRONMENT}

interfaces for interacting with virtual content as AR is one of the ways of mixing the real and virtual world by connecting a video camera to a mobile phone and rendering virtual model on top of the video feeds [10]. Then, the users can view the real world with added computer graphic and audio from the phone screen.

One of the challenges in AR applications is how user interface interaction attracts the users to immerse in AR mobile application. There are some suggestions of approach and solution to this problem. One of the most suitable approaches is to use button [11]. The popular game or application that brought AR mobile application into the crowd is Pokémon GO and Dulux Visualiser MY. In both cases, the users have to use the on-screen button to interact with the application. Pokémon GO is an adventure mobile game application played by catching the Pokémon in a real surrounded with the superimposed virtual objects into the users' environment.

The MagicBook [12] uses a completely different approach. This technology consists of handheld augmented reality display (HHD), a computer graphic workstation and a physical book. MagicBook allows the users to experience the full reality-virtually continuum by moving seamlessly from AR to virtual reality. MagicBook is only an early attempt at a transitional interface for viewing spatial data set; it supports the collaboration of multiple levels. There are many improvements that need to be done, especially in the interface's interaction with the users.

A handheld device especially the mobile phone has become a phenomenon, thus proving that a handheld device is very suitable interaction medium in $\mathrm{AR}$ application. A study on interaction techniques using the handheld device as a user input device to a large display environment proposed three intuitive interactions namely motion-flow based approach, marker-object approach and marker-cursor approach [13]. Each interaction method can be applied to many applications creatively by combining it with various capabilities of a handheld device such as vibration feedback, simple gesture recognition and GPS. The outcome of this study is still ambiguous as the formal usability analysis is on-going.

Mobile phone-based augmented reality application enables the users to view the complex model using their phone. In 14] explored how AR technology can be deployed to provide assistance with real-world intuitively by assemble, repair and training task. The system was implemented by the client-server architecture using a thin client on a mobile phone connected to a remote PC server. Noticeably, image captured from the phone was delayed for a few seconds, disturbed the system performance. However, most pilot study users mostly agreed that the AR interface is really helpful in helping them completing a real-world assembly task.

User interface plays a key role in the AR application for the users to really enjoy playing games. User interface issue in mobile based AR games [15] with high tangibility of device and its button interface makes an interesting comparison in manipulation technique. The study pointed out a variety of methods for rotation and translation of virtual object with the aim to develop input techniques using one hand that rely on a joypad and keypad input only. The result from the study identified many advantages of implementing tangible interface metaphor for virtual object rotation. However, the speed and accuracy affected the system performance as it provided a full six degrees of freedom input making the system to need a more precise input that must correctly align with the models.

An integrated camera commonly found in the mobile phone can be used for a new type of interface in the mobile AR game. In [16] developed and compared three human interfaces appropriate for a mobile phone game application. However, there were many constraints using mobile phones such as consideration of screen resolution, memory restriction, processor constraint and download option. The study then developed a mobile AR game where the users have to control the movement of the ball through a physical maze by tilting the maze by hand. The result acquired from the study showed a particular slow response time for the game and did not match the performance and dynamic of the traditional types of game. From the three proposed interfaces, the best selection was the tilt interface as it maintained the users' interest by providing suitable challenges during the game process.

\section{EXPERIMENTAL SETUP}

The participants in this study were preschool students and teachers in primary school in Johor, Malaysia. Data was collected from the five teachers and 15 preschool students, nine females and six males in Sekolah Kebangsaan Seri Kampung Renggam. The school is located in rural area and listed as low enrolment schools classified by the Ministry of Education Malaysia with only 92 enrolments from whole school based on Student Management Module (APDM) on January 2019. Table 1 presents the demographic information on the population from which the sample subjects were analysed for this study.

The sample group was identified through convenience sampling (willingness to participate). This technique is a non-probability sampling that is fast, inexpensive and easy to employ as the subject group is readily available and accessible. Before starting the AR mobile application testing, the students were tested to determine their level of writing and reading skill to develop an AR mobile application that suits the preschool student syllabus and level of cognitive learning style.

The students were asked to read and write basic words and alphabets individually. Then, the students were introduced to AR mobile-based application and received training on how to deploy the application as all the participants were freshman and the first-time users of AR technology. After all learning activities were finished, all participants took a post-test; the test questions were similar to those used to assess students' level in writing and reading basic word and alphabet. Finally, the students filled out learning satisfaction questionnaire with the help of teacher and researcher. 
Table 1: Demographic information of school site

\begin{tabular}{|c|c|c|c|c|c|}
\hline \multirow{2}{*}{ School Name } & \multicolumn{2}{|c|}{ Gender } & \multicolumn{2}{|c|}{ Age } & \multirow{2}{*}{ Total } \\
\cline { 2 - 5 } & $\mathrm{L}$ & $\mathrm{P}$ & $5 \mathrm{y} / \mathrm{o}$ & $6 \mathrm{y} / \mathrm{o}$ & \\
\hline $\begin{array}{c}\text { Sekolah Kebangsaan } \\
\begin{array}{c}\text { Seri Kampung } \\
\text { Renggam (SKSKR) }\end{array}\end{array}$ & 6 & 9 & 8 & 7 & 15 \\
\hline
\end{tabular}

- L (Male), P (Female)

\section{LEARNING PERFORMANCE ASSESSMENT \& RESULTS}

The data sources consist of formal and informal interviews, direct observation, site document, document analysis and questionnaire. This study conducted a direct observation in the classroom to identify student interaction throughout school time, teacher-student interaction and teaching techniques used in the English classroom. Interviews were conducted with: (1) 4 participating teacher, and (2) group of preschool students. Both interviews were structured based on a set of questionnaires generated from the research questions and objectives. All interviews were voice recorded while taking notes on the responses given during the interview process. The observation was conducted using observational protocol corresponding to the research questions and conceptual framework. Observation notes, field note, and voice data were compiled for withincase data analysis and cross-case analysis.

A paired t-test was used to compare the data collected from the sample test. Results of the pre-test and post-test are shown below, which comprised the data collected with the $\mathrm{n}=15$ students

Table 1: Results of the pre-test and post-test

\begin{tabular}{|c|c|c|c|}
\hline Person & Pre-Test Score & Post-Test Score & Difference \\
\hline 1 & 5 & 7 & +2 \\
\hline 2 & 6 & 6 & 0 \\
\hline 3 & 3 & 5 & +2 \\
\hline 4 & 8 & 9 & +1 \\
\hline 5 & 10 & 12 & +2 \\
\hline 6 & 12 & 11 & -1 \\
\hline 7 & 9 & 12 & +4 \\
\hline 8 & 5 & 7 & +2 \\
\hline 9 & 7 & 7 & 0 \\
\hline 10 & 4 & 5 & +1 \\
\hline 11 & 8 & 9 & +1 \\
\hline 12 & 5 & 7 & +2 \\
\hline 13 & 2 & 3 & +1 \\
\hline 14 & 4 & 5 & +1 \\
\hline 15 & 3 & 3 & 0 \\
\hline Total & 91 & 108 & \\
\hline
\end{tabular}

The mean and standard deviation of the different calculation are shown in Table 3.

Table 3: Results of the learning performance based on paired t-test

\begin{tabular}{|c|c|c|}
\hline Group & Pre-Test & Post-Test \\
\hline Mean & 6.07 & 7.20 \\
\hline Variance & 8.21 & 8.46 \\
\hline SD & 2.87 & 2.91 \\
\hline
\end{tabular}

\begin{tabular}{|c|c|c|}
\hline SEM & 0.74 & 0.75 \\
\hline $\mathrm{N}$ & 15 & 15 \\
\hline $\mathrm{t}$ & \multicolumn{2}{|c|}{4.1405} \\
\hline degree of freedom & \multicolumn{2}{|c|}{14} \\
\hline Critical Value & \multicolumn{2}{|c|}{4.14} \\
\hline $\mathrm{P}(\mathrm{t}<=$ two tail $)$ & \multicolumn{2}{|c|}{0.001} \\
\hline
\end{tabular}

The two-tailed $\mathrm{P}$ value was equal to 0.0010 ; by conventional criteria, this difference is considered extremely statically significant. Confidence interval: the mean of pretest minus post-test equals to -1.1333 and $95 \%$ confidence intervals of this difference start from -1.72 to -0.55 . The intermediate value used in the calculation, $t$ equal to 4.1405 and d.o.f equal to 14. The absolute value of the calculated $t$ exceeded the critical value $(4.1405>4.14)$, which was significantly different. In another word, the learning mode generated good learning performance.

\section{CONCLUSION}

The AR mobile-based application has showed an instant effect as there was a slight enhancement in student mastery in simple word and alphabet. Besides, AR mobile-based application helped the teacher in teaching simple English words in interactively fun ways compared to the conventional learning technique. The teacher said that having changes once a while is a good thing to as long as it is beneficial for the students' learning. For the other sides, the students can broaden the usage of mobile phone from social media and games to learning in interactive and positive ways. Moreover, there was a slight enhancement in student proficiency in English words and alphabets proven from the test conducted before and after interaction with the AR application. Augmented reality technology enhanced student concentration in learning as they are explorative and energetic after using the application.

This AR mobile-based application provides an appropriate way for the teacher to teach preschool students in the rural area. The existence of this study can help the students to use the mobile phone in a beneficial way of encouraging the learning process. Hopefully, this application can help to spark the researchers in intrigue their attention towards extended and enhancement usage of a virtual button in the virtual environment.

There a little suggestion that can be made to upgrade the mobile phone application to be more efficient and interactive in the future. Some suggestions that need to be considered are:

i. Implementing mobile AR games in shared spaces.

ii. Adding more functionality on the system in terms of auditory, sensory and visual.

iii. Experimental setup can be broadened to learn more complicated words and many subjects including Mathematics and Science.

\section{ACKNOWLEDGMENT}

The research paper supported by University Sultan Zainal Abidin (UniSZA) using SRGS Research Grant Fund, project 
number: UniSZA/2017/SRGS/06. Special Thanks to the Ministry of Education Malaysia (MOE) and Research Management, Innovation and Commercialisation Centre (RMIC) UniSZA for providing financial support for the research.

\section{REFERENCES}

1. R. T. Azuma, "A survey of augmented reality," Presence: Teleoperators and Virtual Environments, 6(4), 2007, pp. 355385.

2. N. N. Zolkefly, I. Ismail, S. Safei, and S. N. W. Shamsuddin, "Head gesture recognition and interaction techniques in virtual reality: A review, " International Journal of Engineering and Technology (UAE), 7, 2018, pp. 437-440.

3. P. S. Rajendran, I. S. Christian, and M. S. Shedge, "AREDAI Augmented Reality Based Educational. Artificial Intelligence System, "International Journal of Recent Technology and Engineering, 8(1), 2019, pp. 1960-1964.

4. Feng Zhou, H. B. Duh, and M. Billinghurst, "Trends in augmented reality tracking, interaction and display: A review of ten years of ISMAR," 7th IEEE/ACM International Symposium on Mixed and Augmented Reality, 2008, pp. 193202.

5. J. Alexander, J. Hardy, and S. Wattam, "Characterizing the physicality of everyday buttons," 9th ACM International Conference on Interactive Tabletops and Surfaces, 2014, pp. 205-208.

6. J. R. Vallino, and C. M. Brown, Interactive augmented reality. $\mathrm{PhD}$ thesis, New York: University of Rochester, 1998.

7. K. Kim, M. Billinghurst, G. Bruder, H. B. Duh, and G. F. Welch, "Revisiting trends in augmented reality research: A review of the 2nd decade of ISMAR (2008-2017)," IEEE Transactions on Visualization and Computer Graphics, 24(11), 2018, pp. 2947-2962.

8. R. Azuma, Y. Baillot, R. Behringer, S. Feiner, S. Julier, and B. MacIntyre, "Recent advances in augmented reality," IEEE Computer Graphics and Applications, 21(6), 2001, pp. 34-47.

9. L. Vera, J. Gimeno, I. Coma, and M. Fernández, "Augmented mirror: interactive augmented reality system based on kinect," IFIP Conference on Human-Computer Interaction, 2011, pp. 483-486.

10. A. Rösler, Augmented reality games on the iPhone. Bachelor thesis, Sweden: Blekinge Institute of Technology, 2009.

11. R. M. Gabarró, Interactive augmented reality. Master thesis, Stockholm: Royal Institute of Technology, 2010.

12. M. Billinghurst, H. Kato, and I. Poupyrev, "The MagicBook moving seamlessly between reality and virtuality," IEEE Computer Graphics and Applications, 21(3), 2001, pp. 6-8.

13. S. Jeon, J. Hwang, G. J. Kim, and M. Billinghurst, "Interaction techniques in large display environments using hand-held devices," ACM Symposium on Virtual Reality Software and Technology, 2006, pp. 100-103.

14. M. Hakkarainen, C. Woodward, and M. Billinghurst, "Augmented assembly using a mobile phone," 7th IEEE/ACM International Symposium on Mixed and Augmented Reality, 2008, pp. 167-168.

15. A. Henrysson, M. Billinghurst, and M. Ollila, "Virtual object manipulation using a mobile phone," International Conference on Augmented Tele-Existence, 2005, pp. 164-171.

16. S. Bucolo, M. Billinghurst, and D. Sickinger, "User experiences with mobile phone camera game interfaces," 4th International Conference on Mobile and Ubiquitous Multimedia, 2005, pp. 87-94. 